\title{
CONCLUSION
}

\section{SEISMIC DESIGN OF DUCTILE MOMENT RESISTING REINFORCED CONCRETE FRAMES}

\author{
R. J. Burns*
}

As convenor of the Society's discussion group responsible for the series of papers on Seismic Design of Ductile Moment Resisting Reinforced Concrete Frames, I would like to conclude the series with the following comments:

In the June, 1977 issue (Vol. 10, No. 2) the series of papers was introduced and the philosophy and aims of the exercise explained. Eight technical papers have now been published covering most aspects of the design of reinforced concrete frame buildings to comply with the seismic provisions of NZS 4203 . The FOUNDATIONS paper (Section $J$ ) in this issue is the last to be approved by the group for publication. Papers dealing with ANALYSIS (Section B) and LOW DUCTILE FRAMES (Section L) will not be published due to difficulties and delays in reaching a consensus of opinion. The discussion group has been disbanded and work is proceeding in preparation for Workshops to be held in Auckland and wellington later this year.

The original objectives in forming the discussion group - to clarify some 'grey areas' in design, agree to interpretations of specific clauses in NZS 4203, and to produce simple guide lines for designers - have, I fear, been only partly met. When looking at the membership of the group you will appreciate that discussion was very lively at times with extreme points of view on certain topics difficult if not impossible to reconcile. The results, however, should benefit all designers working to our new loadings code, and also those responsible for checking and approving designs by others. Certainly, the philosophy behind NZS 4203 should be better understood.

It is unfortunate that the current building recession has given only limited opportunities for designers to apply the methods in practice. There has been very little feed back in the form of discussion through the Bulletin. This is a topic where discussion should not close and authors should have the opportunity to update their papers in the light of new information. Comment from overseas interests would be particularly welcome.

In recent years New Zealand has made some significant contributions to earthquake engineering knowledge - recognising biaxial effects, beam/column joint problems and in developing capacity design techniques, to name a few. The codification of these has not always had the support of exhaustive laboratory tests or comprehensive computer analysis, and in this respect we should remind ourselves that theory rather than performance provides the basis for some important sections of our codes. To quote from our President's annual report, referring to the discussion group, "....members spent many hours in preparing drafts and searching for reasonable answers to problems, many of which are on the very fringe of our current knowledge."

On behalf of the Management Committee I would like to thank all members of the group for the considerable time and effort they made available to this exercise.

Workshops to demonstrate the practical application of these papers will be held in Wellington in October (16-18th) and in Auckland in November (13-15th) with a further one planned for Christchurch early in 1979. Participants at each will be limited to 30 to maintain a workshop atmosphere. Depending on the success of these, further workshops may be held in other centres later.

* Consulting Engineer, Wellington. 